\title{
Estimating forest antelope population densities using distance sampling with camera traps
}

\author{
Rajan Amin, Hannah Klair, Tim Wacher, Constant Ndjassi \\ Andrew Fowler, David Olson and Tom Bruce
}

\begin{abstract}
Traditional transect survey methods for forest antelopes often underestimate density for common species and do not provide sufficient data for rarer species. The use of camera trapping as a survey tool for medium and large terrestrial mammals has become increasingly common, especially in forest habitats. Here, we applied the distance sampling method to images generated from camera-trap surveys in Dja Faunal Reserve, Cameroon, and used an estimate of the proportion of time animals are active to correct for negative bias in the density estimates from the 24-hour camera-trap survey datasets. We also used multiple covariate distance sampling with body weight as a covariate to estimate detection probabilities and densities of rarer species. These methods provide an effective tool for monitoring the status of individual species or a community of forest antelope species, information urgently needed for conservation planning and action.
\end{abstract}

Keywords Abundance, antelope, camera trap, Cameroon, Central Africa, distance sampling, Dja Faunal Reserve, forest

\section{Introduction}

A ntelopes and other artiodactyl species constitute a significant component of forest and woodland ecosystems both in terms of biomass (White, 1994) and ecological services (Feer, 1995). Many species are increasingly threatened by habitat loss and hunting for bushmeat (East, 1998). Forest antelopes are primary targets for the trade in bushmeat (Wilkie \& Carpenter, 1999; Fa et al., 2005) and have undergone major local and regional declines as a result (e.g. van Vliet et al., 2007). Therefore, monitoring the status of forest antelopes is a critical conservation need. However, forest antelopes are difficult to monitor using traditional methods based on direct sightings or signs as many species are solitary, nocturnal, shy, spend long periods

RAJAN AMIN (Corresponding author, (1) orcid.org/0000-0003-0797-3836), HanNah Klair and Tim Wacher (D) orcid.org/0000-0002-5552-7577) Zoological Society of London, Regents Park, London NW1 4RY, UK

E-mail raj.amin@zsl.org

Constant Ndjassi, Andrew Fowler and Tom Bruce (10) orcid.org/0000-00016958-1657) Zoological Society of London, Cameroon Office, Yaoundé, Cameroon

David Olson WWF-Hong Kong, Kwai Chung, Hong Kong

Received 16 July 2020. Revision requested 7 August 2020.

Accepted 15 October 2020. First published online 26 July 2021. concealed in dense vegetation, and the spoor and droppings are difficult to identify to species level with confidence (Rovero \& Marshall, 2004; Croes et al., 2007; van Vliet et al., 2008; Jost Robinson et al., 2017). DNA-based amplification of species-specific mitochondrial DNA fragments from droppings is possible, but time-consuming, expensive, and largely impractical with currently available analysis techniques (e.g. Breuer \& Breuer-Ndoundou Hockemba, 2012; Bowkett et al., 2013; Bourgeois et al., 2019). Here, we present a method based on distance sampling with images from camera traps to obtain density estimates of forest antelopes. We demonstrate its use for monitoring the status of threatened forest antelopes in the Dja Faunal Reserve, southern Cameroon.

\section{Study area}

The Dja Faunal Reserve is the largest protected area in Cameroon $\left(5,260 \mathrm{~km}^{2}\right.$; Fig. 1). The Reserve, a World Heritage Site, has high levels of both flora and fauna diversity, with 107 known mammal species (UNESCO, 2018). Ten species of forest antelopes occur in the Reserve, from the largest (the Near Threatened bongo Tragelaphus eurycerus) to one of the smallest (Bates pygmy antelope Neotragus batesi) (Table 1). All these antelope species are hunted for bushmeat. Other threatened species include the Critically Endangered western lowland gorilla Gorilla gorilla gorilla and African forest elephant Loxodonta cyclotis, and the Endangered central chimpanzee Pan troglodytes troglodytes (Bruce et al., 2017, 2018). Dja Faunal Reserve comprises round-topped hills of $600-800 \mathrm{~m}$ altitude, with valleys on either side of a central east-west ridgeline (MINFOF \& IUCN, 2015). The predominant habitat within the Reserve is mixed species rainforest with swamp habitats and some periodically flooded forest patches in valley areas. Mean total annual rainfall is c. $1,600 \mathrm{~mm}$. The Reserve faces many pressures. The surrounding human population is increasing and industries, such as logging, rubber extraction, hydropower, and mining are proliferating, resulting in increased demand for bushmeat. Both illegal subsistence and commercial hunting occur within the Reserve.

\section{Methods}

\section{Distance sampling with camera-trap images}

We applied the distance sampling method of Howe et al. (2017), who processed video sequences, adapted here for 


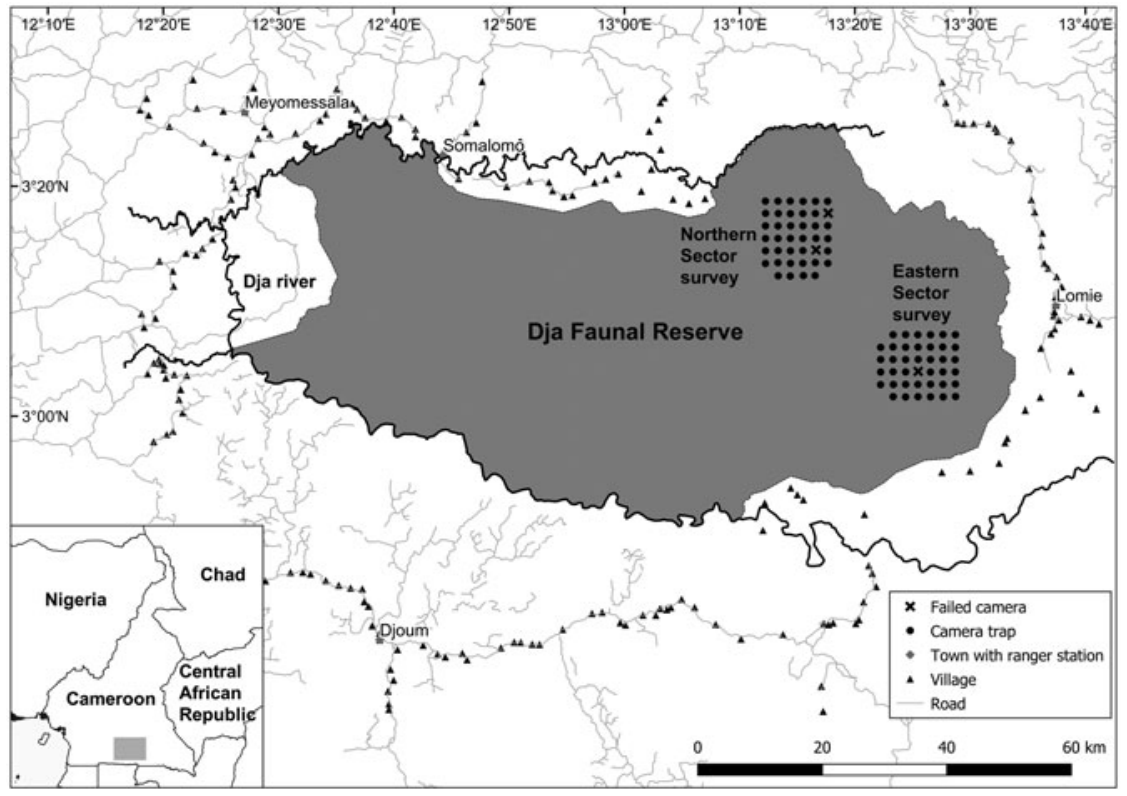

FIG. 1 Location of the two grids, each containing 40 camera traps, deployed in the northern and eastern sectors of Dja Faunal Reserve, Cameroon.

TABLE 1 The 10 forest antelope species detected by camera traps in the northern and eastern sectors of Dja Faunal Reserve, Cameroon (Fig. 1), with the species' IUCN Red List status, mean body weights (from Kingdon \& Hoffmann, 2013), and details of detections.

\begin{tabular}{|c|c|c|c|c|}
\hline \multirow[b]{2}{*}{ Species } & \multirow{2}{*}{$\begin{array}{l}\text { IUCN Red List } \\
\text { status (trend) }\end{array}$} & \multirow{2}{*}{$\begin{array}{l}\text { Mean body } \\
\text { weight }(\mathrm{kg})\end{array}$} & \multicolumn{2}{|c|}{$\begin{array}{l}\text { Number of camera placements } \\
\text { with detections (number of } \\
\text { camera triggers) }\end{array}$} \\
\hline & & & Northern & Eastern \\
\hline Peters' duiker Cephalophus callipygus & LC (decreasing) & 19.6 & $30(3,239)$ & $33(1,795)$ \\
\hline Bay duiker Cephalophus dorsalis & NT (decreasing) & 19.0 & $31(751)$ & $12(86)$ \\
\hline Bates pygmy antelope Neotragus batesi & LC (unknown) & 2.2 & $6(21)$ & $7(111)$ \\
\hline White-bellied duiker Cephalophus leucogaster & NT (decreasing) & 15.5 & $5(47)$ & $4(14)$ \\
\hline Black-fronted duiker Cephalophus nigrifrons & LC (decreasing) & 13.8 & $4(23)$ & $5(30)$ \\
\hline Yellow-backed duiker Cephalophus silvicultor & NT (decreasing) & 66.5 & $28(540)$ & $20(287)$ \\
\hline Water chevrotain Hyemoschus aquaticus & LC (decreasing) & 12.1 & $3(8)$ & $1(17)$ \\
\hline Blue duiker Philantomba monticola & LC (decreasing) & 4.8 & $30(6,521)$ & $35(2,296)$ \\
\hline Bongo Tragelaphus eurycerus & NT (decreasing) & 229.0 & $2(7)$ & $0(0)$ \\
\hline Sitatunga Tragelaphus spekii & LC (decreasing) & 45.0 & $5(23)$ & $1(5)$ \\
\hline
\end{tabular}

${ }^{1}$ LC, Least Concern; NT, Near Threatened.

actively triggered still images (see below) from camera-trap surveys, and used estimates of the overall proportion of time animals are active, and thus available for detection, to correct for negative biases in density estimates from 24-hour datasets. We used multiple covariate distance sampling to estimate detection probabilities and densities from the combined dataset of multiple species to provide improved density estimates for species with fewer observations.

Each deployed camera in a survey is treated as a point transect. The cameras were programmed to record a set number of still images at a fixed time interval between images when triggered and with a short latent period $t_{q}$ between triggers. The temporal effort for each camera is then equal to the camera operation period $T$ divided by the time period between two consecutive triggers $T_{t}$. This represents the maximum possible number of triggers. The time period between successive triggers should be sufficiently short so that an animal is unlikely to pass completely through without being detected by the camera (Howe et al., 2017, used $2 \mathrm{~s}$ as a snapshot). The spatial coverage is the fraction of a circle covered by a camera, which is given by the horizontal angle of view (field of view) divided by 360 degrees (two radians). The overall sampling effort at a camera is the temporal effort multiplied by the spatial coverage.

Observations of the species of interest were taken from the first image of each trigger when it was detected by the camera. The standard assumptions of distance sampling hold (Buckland et al., 2001; Howe et al., 2017): (1) animals at the sampling point are detected with certainty, (2) animals are detected at their initial location, prior to any movement, 
(3) distances are measured accurately, and (4) sampling points are placed independently of animal locations. The first assumption could be violated by animals passing beneath the camera field of view, failure to identify the species because only part of the animal is visible, and possibly the delay between the time the sensor is activated and the time the first image is recorded. The violation of the first assumption may be detectable during exploratory data analysis in the form of fewer than expected detections close to the sampling point, and bias can be avoided via left-truncation in which these detections are excluded from the analysis. To avoid violating the second and third assumptions, the distance to the animal in only the first image in a trigger sequence is included in the analysis. To assign animals in images accurately to distance intervals, reference images are taken at camera deployment, recording horizontal distances and angles from the camera using a measuring tape and a pole (see below for details). Systematic or random camera-trap survey designs are consistent with the assumption that sampling points are placed independently of animal locations. Cameras are not intentionally placed to target habitat features known to be either preferred or avoided by the animals of interest (Howe et al., 2017).

A significant advantage of camera traps is that they operate 24 hours per day and record data on multiple species. However, data on rarer species may be insufficient to fit detection functions to obtain reliable density estimates. Multiple covariate distance sampling allows probability of detection to be modelled as a function of additional covariates; in this study we used (1) species as a factor and (2) species body weight as a continuous variable (Marques et al., 2007). Additionally, the overall proportion of time a species is active can be estimated directly from the camera-trap data by fitting a circular kernel distribution, thus allowing the complete 24 -hour data to be used.

\section{Density estimate of forest antelopes}

We used point transect distance sampling methods to estimate the densities of forest antelope species in the Dja Faunal Reserve. We deployed a systematic grid of 40 Bushnell Trophy Aggressor Low Glow cameras (Bushnell Outdoor Products, Overland Park, USA) at $2 \mathrm{~km}$ spacing during 22 January-8 May 2018 in the northern sector and from 27 January-17 May 2018 in the eastern sector of the Reserve (Fig. 1). This design was consistent with the assumption that sampling points are placed independently of animal locations. A single camera was placed at a height of c. $30 \mathrm{~cm}$ as close to the grid sampling point as possible, with a consistent and unobstructed field of view. The cameras were programmed to take three images per trigger, with a $2 \mathrm{~s}$ delay before the camera could be triggered again. This resulted in a $5 \mathrm{~s}$ time interval between consecutive triggers, to minimize the chance that an animal could pass without being detected by the camera. We also expect any bias in the density estimate as a result of this issue to be small. The camera field of view was 35 degrees.

During installation of each camera, we took reference images with a 1-m pole placed at distances of 1, 1.5, 2, 3, 4, 5 and $6 \mathrm{~m}$ from the camera at o degrees and at 15 degrees either side of the centre of the field of view. Distance reference points were then identified from the reference images and superimposed on all subsequent survey images using the marker tool of EpiPen Basic (Tank Studios, Edinburgh, UK). We assigned the nearest animal in the first image of a trigger to the appropriate distance band $(0-2,2-3,3-4,4-5,5-6,>6 \mathrm{~m})$ based on the position of its feet relative to the reference marker points.

We excluded data recorded on day of camera deployment or retrieval, to allow animals to become accustomed to the cameras in their environment, the smell of humans to dissipate, and to avoid any influence on the data as a result of disturbing animals while approaching a camera to recover it. We fitted point transect models in Distance 7.o (Thomas et al., 2010). Firstly, we performed conventional distance sampling analyses for each species with sufficient detections, to compare densities between the northern and eastern sectors using sector as the stratum. We considered models of the detection function for the combined data from the two camera grids with the half-normal, hazard rate, and uniform key functions with up to five cosine, simple polynomial and Hermite polynomial adjustment terms. Adjustment terms were constrained, where necessary, to ensure the detection function was monotonically decreasing. We selected among candidate models of the detection function by comparing AIC values, acknowledging the potential for overfitting as many observations were not independent (Howe et al., 2017). Secondly, we analysed the combined forest antelope species dataset and the two sectors using the multiple covariate distance sampling engine in Distance, to obtain density estimates for the rarer species with fewer detections. We assumed species body weight influences the scale of the detection function but not its shape, and we used both global and separate estimation of the species detection function.

We fitted a circular kernel distribution to individual species activity pattern using the activity package (Rowcliffe et al., 2014) in $R$ 4.0.2 (R Development Core Team, 2020). We subsequently divided the density estimates with estimates of the proportion of time species are active. We assumed that all individuals in the sampled population are active at the peak of the daily activity cycle.

\section{Results}

We recorded all 10 species of forest antelopes known to be present in Dja Faunal Reserve (Table 1). All animals were active when detected. The blue duiker Philantomba monticola was the most frequently recorded forest antelope (Table 1). The bongo, sitatunga Tragelaphus spekii and water 

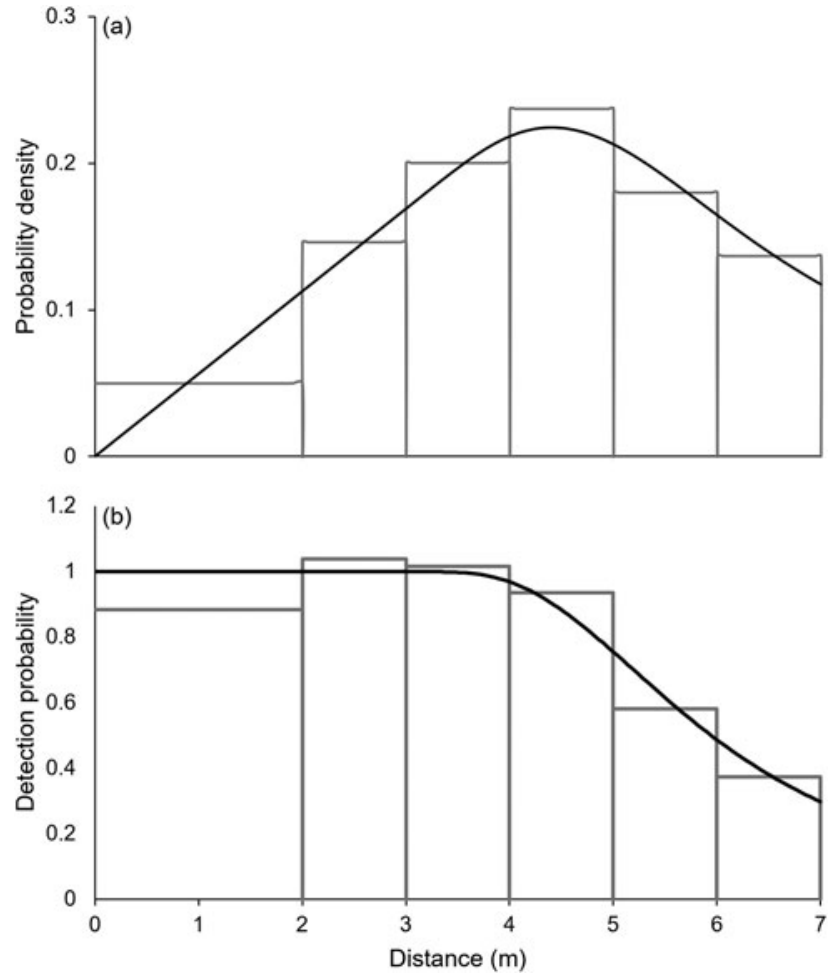

FIG. 2 Probability density function of (a) observed distances and (b) detection probability as a function of distance from hazard-rate point transect model fitted with multiple covariate distance sampling of antelope species in Dja Faunal Reserve.

chevrotain Hyemoschus aquaticus were detected $<30$ times across both camera-trap grids and were therefore not included in the data analysis. Encounter rates were highly variable among locations for the other seven species and did not exhibit an obvious spatial pattern. There was no evidence of spatial autocorrelation (Moran's $I \mathrm{P}>0.05$ ).

Exploratory analyses revealed no evidence of a paucity of observations at $\mathrm{o}-2 \mathrm{~m}$ from the cameras or issues with variation in visibility distances between cameras. The hazard rate model with no adjustments terms minimized AIC for both the conventional distance sampling and the multiple covariate distance sampling analyses (Figs $2 \& 3$ ).

Density estimates for the bay duiker Cephalophus dorsalis, blue duiker, Peters' duiker Cephalophus callipygus, and yellow-backed duiker Cephalophus silvicultor were higher in the northern than the eastern sector. The differences were statistically significant for bay duiker and blue duiker, based on the Wald test $(\mathrm{P}<0.05)$ (Fig. 4).

Overall, blue duiker was the most abundant forest antelope. Peters' duiker had a significantly higher estimated density than Bates pygmy antelope, bay duiker, blackfronted duiker Cephalophus nigrifrons, white-bellied duiker Cephalophus leucogaster, and yellow-backed duiker. Bates pygmy antelope, black fronted duiker and white-bellied dui$\mathrm{ker}$ had densities of $<_{1}$ individual per $\mathrm{km}^{2}$. Proportion of time species were active was $0.15-0.32$ (Table 2). Detection

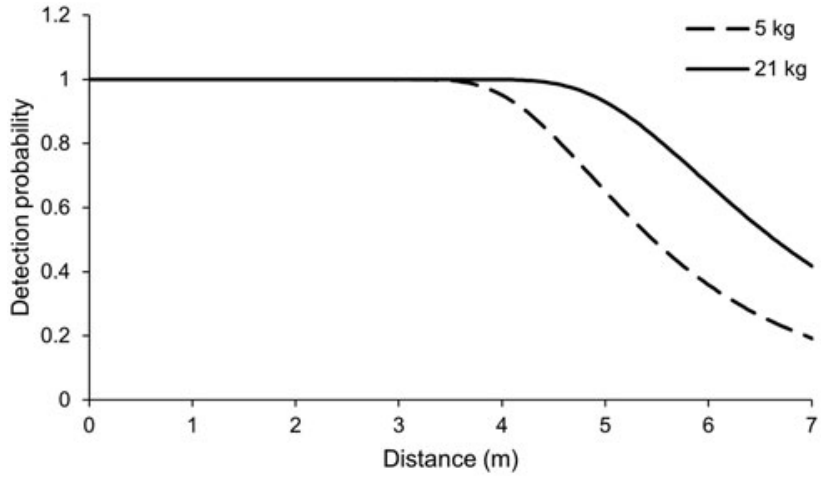

FIG. 3 Detection probabilities for antelopes of 5 and $21 \mathrm{~kg}$ body weight as a function of distance from hazard-rate point transect model fitted with multiple covariate distance sampling in Dja Faunal Reserve.

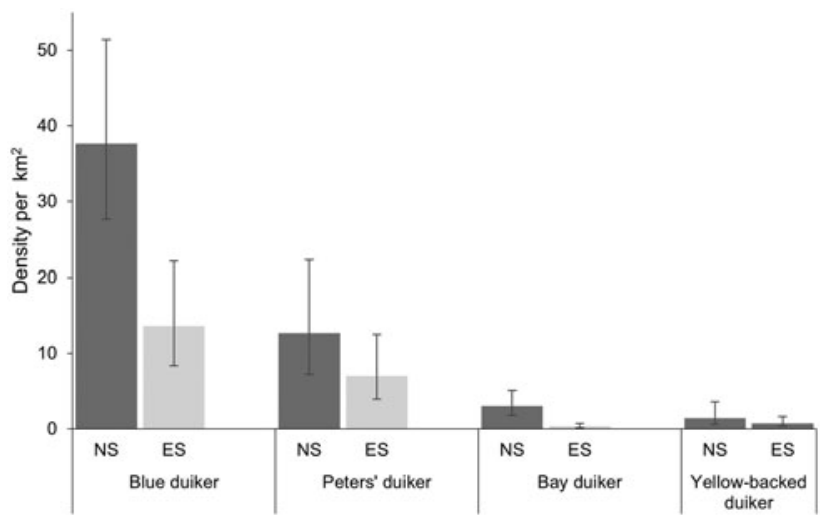

FIG. 4 Between-grid comparison of density estimates with 95\% confidence intervals (using conventional distance sampling) for bay duiker Cephalophus dorsalis, blue duiker Philantomba monticola, Peters' duiker Cephalophus callipygus and yellowbacked duiker Cephalophus silvicultor in the northern sector (NS) and eastern sector (ES) of Dja Faunal Reserve.

probability ranged from 0.62 (Bates pygmy antelope) to 1 (yellow-backed duiker) (Table 2).

\section{Discussion}

In this study, we have shown that camera-trap distance sampling can be an effective method for monitoring the densities and therefore population status of a community of forest antelopes, information urgently needed for conservation planning and action. Data from period of peak activity for most species was insufficient to fit detection models. We therefore used the whole 24-hour dataset by correcting for bias using an estimate of the proportion of time animals are active. We further applied multiple covariate distance sampling on the combined species dataset with body weight as a covariate to estimate densities for rarer species.

Line transect sampling using direct sightings or signs (including DNA based methods) for estimating density of 
TABLE 2 Estimates of proportion of time active during 24 hours and multiple covariate distance sampling model outputs (estimates of density and detection probability, and effective detection radius) for seven forest antelope species in Dja Faunal Reserve.

\begin{tabular}{llcll}
\hline Species & $\begin{array}{l}\text { Proportion of } \\
\text { time active }\end{array}$ & $\begin{array}{l}\text { Density estimate, } \\
\text { individuals per km } \\
(95 \% \mathrm{CI})\end{array}$ & $\begin{array}{l}\text { Detection probability } \\
\text { estimate }(95 \% \mathrm{CI})\end{array}$ & $\begin{array}{l}\text { Effective detection } \\
\text { radius }(\mathrm{m})\end{array}$ \\
\hline Bates pygmy antelope & 0.20 & $0.53(0.20-1.45)$ & $0.63(0.56-0.70)$ & 5.54 \\
Bay duiker & 0.32 & $1.54(0.95-2.52)$ & $0.82(0.80-0.85)$ & 6.36 \\
Black-fronted duiker & 0.23 & $0.15(0.06-0.38)$ & $0.75(0.66-0.86)$ & 6.08 \\
Blue duiker & 0.26 & $26.06(19.52-34.79)$ & $0.65(0.64-0.66)$ & 5.66 \\
Peters' duiker & 0.32 & $9.30(6.13-14.12)$ & $0.83(0.82-0.84)$ & 6.38 \\
White-bellied duiker & 0.15 & $0.25(0.10-0.60)$ & $0.80(0.71-0.89)$ & 6.25 \\
Yellow-backed duiker & 0.26 & $1.56(0.82-2.96)$ & 1.00 & 7.00 \\
\hline
\end{tabular}

TABLE 3 Density estimates of blue duiker obtained in Central Africa using line transect sightings and dung count surveys.

\begin{tabular}{lllll}
\hline & Density, individuals & & & \\
Site & per $\mathrm{km}^{2}(95 \% \mathrm{CI})$ & $\mathrm{CV}(\%)$ & Method & Source \\
\hline Cross River National Park, Nigeria & $15.5(7.8-30.9)$ & Not reported & Sightings & Jimoh et al. (2011) \\
Bouma Bek National Park, Cameroon & $6.9(4.4-10.7)$ & 21.5 & Dung & Kamgaing et al. (2018) \\
Bouma Bek National Park, Cameroon & $3.5(1.9-6.6)$ & 31.6 & Sightings (daytime) & Kamgaing et al. (2018) \\
Bouma Bek National Park, Cameroon & $59.8(46.3-77.4)$ & 12.8 & Sightings (night-time) & Kamgaing et al. (2018) \\
Moukalaba-Doudou National Park, Gabon & $16.4(11.4-23.6)$ & Not reported & Sightings (daytime) & Nakashima et al. (2013) \\
Korup National Park, Cameroon & 1.5 & 107.3 & Dung & Viquerat et al. (2012) \\
Korup National Park, Cameroon & 8.3 & 45.3 & Sightings (daytime) & Viquerat et al. (2012) \\
Korup National Park, Cameroon & 6.8 & 53.1 & Sightings (night-time) & Viquerat et al. (2012) \\
\hline
\end{tabular}

forest antelopes has severe limitations in terms of reliability, and/or cost and effort (Rovero \& Marshall, 2004; Lwanaga, 2006; Waltert et al., 2006; Rovero \& Marshall, 2009; Elenga et al., 2020). Despite the high initial set-up costs of cameratrap surveys, there are multiple advantages in terms of reliability of data gathered, long-term cost efficiency, and the large number of species that can be surveyed using a single technique (Amin et al., 2018). Our line transect surveys cost c. EUR 38,000 in the Dja Faunal Reserve compared to EUR 15,300 for a camera-trapping grid of 40 cameras, including costs of buying cameras and accessories, deployment and retrieval, training and analysis. Seven such camera-trap grids would be required to adequately cover Dja Faunal Reserve. Each subsequent grid would cost c. EUR 8,700, including the costs of replacing damaged cameras, assuming five replacements are required per deployment. In terms of application in the field, it is less labour intensive to train surveyors to deploy camera traps than to train them in line transect skills. For example, during this study a 5-day training session was adequate for setting up cameras. This training enabled five teams, each comprising two trained personnel, to deploy the camera-trap grids. During the analysis phase uncertain species identifications can be independently validated by experts, which increases the confidence of the estimates generated using this method (Amin et al., 2016). There is the potential for camera-trap distance sampling to be used to obtain density estimates for other species of conservation concern such as elephants, great apes and pangolins (Cappelle et al., 2019).

Comparing density estimates with other sites is challenging because of the paucity of data on forest antelope populations. This problem is further compounded by a lack of standardization of monitoring methods such as daytime transects and night-time transects using spotlights, and reporting (Waltert et al., 2006; Kamgaing et al., 2018; O’Brien et al., 2019). Several studies have only been able to estimate abundance of generic red duiker species because species often cannot be distinguished in brief glimpses in the field (Yasouka, 2006; Nakashima et al., 2013; Kamgaing et al., 2018). This means that only estimates of the common diurnal blue duiker populations can be confidently compared between our study and studies that have used line transect methods in Central Africa (Table 3). The combined northern and eastern sector blue duiker population density estimate of 26.06 individuals per $\mathrm{km}^{2}$ ( $95 \%$ CI 19.52-34.79) is comparable to estimates from less disturbed parks of Gabon and higher than for some protected areas where there is extensive hunting, such as Korup National Park in Cameroon (Table 3).

Our study revealed that the eastern sector of the Dja Faunal Reserve has significantly lower densities of forest antelopes than the northern sector. This is probably a result of the many roads and trails leading into the eastern sector (it is the only part of the Reserve not surrounded by the Dja 
River). Declines in forest antelope populations associated with hunting pressure have been documented in other parts of Central Africa (Remis, 2000; Remis \& Kpanou, 2011; Garande-Vega et al., 2016). It is unlikely that the differences in forest antelope density between the two cameratrap grids was primarily a result of habitat differences, as blue and red duiker species reach high densities in logged forests and disturbed habitat when poaching is limited (van Vilet \& Nasi, 2008; Clark et al., 2009; Poulsen et al., 2011). Given the relatively intact nature of Dja Faunal Reserve, we would expect consistent densities of duikers between the sectors in the absence of hunting. Therefore, it is not unreasonable to hypothesize that anthropogenic impacts are affecting the density and distribution of forest antelopes, particularly duikers, within the Reserve.

Given that forest antelopes comprise a large proportion of the biomass and volume of bushmeat removed from Central African forests for local consumption and trade, they are important for the food security of an increasing human population. The lack of historical census data and increasing consumer demand could result in declines of these forest species going undetected. The development of tools such as applied in this study to monitor the status of forest antelopes effectively will help in informing much needed conservation efforts. Well-designed camera-trap surveys can help in the identification and testing of the significance of predictors of antelope abundance, such as distance from roads and settlements, logging operations, and hunting intensities, and these techniques are likely to be applicable in forest habitats on all continents.

Acknowledgements We thank Professor Steve Buckland for his advice, the Cameroon Ministry of Forests and Fauna and the late Conservator Hilaire Ndinga of the Dja Faunal Reserve for support, and the Ministry ecoguards and local porters who accompanied the survey teams in the field.

Author contributions Study design: RA, TB, TW, DO, AF, CN; fieldwork: TB, CN; camera-trap data image processing, species identification: TB, CN, HK; data analysis: RA; writing: RA, TW, HK, DO, AF, TB.

\section{Conflicts of interest None.}

Ethical standards This research abided by the Oryx guidelines on ethical standards.

\section{References}

Amin, R., Bowkett, A.E. \& Wacher, T. (2016) The use of camera-traps to monitor forest antelope species. In Antelope Conservation: From Diagnosis to Action (eds J. Bro-Jørgensen \& D.P. Mallon), pp. 190-216. John Wiley \& Sons, Ltd, Hoboken, USA. Amin, R., Wacher, T., Bowkett, A.E., Ogwoka, B., Morris, M. \& Agwanda, B.R. (2018) Africa's forgotten forests: the conservation value of Kenya's northern coastal forests for large mammals. Journal of East African Natural History, 107, 41.
Bourgeois, S., Senn, H., Kaden, J., Bunnefeld, N., Cusack, J., Jeffery, K.J. et al. (2019) Improving cost-efficiency of non-invasive genotyping using fecal samples: new tools for elephant species. PLOS ONE, 14, eo210811.

Bowkett, A.E., Jones, T., Laizzer, R.L., Plowman, A.B. \& Stevens, J.R. (2013) Can molecular data validate morphometric identification of faecal pellets in Tanzanian forest antelope species? Conservation Genetics Resources, 5, 1095-1100.

Breuer, T. \& Breuer-Ndoundou Hockemba, M. (2012) Intrasite variation in the ability to detect tropical forest mammals. African Journal of Ecology, 50, 335-342.

Bruce, T., Amin, R., Wacher, T., Fankem, O., Ndjassi, C., NGo BAtA, M. et al. (2018) Using camera trap data to characterise terrestrial larger-bodied mammal communities in different management sectors of the Dja Faunal Reserve, Cameroon. African Journal of Ecology, 56, 759-776.

Bruce, T., Wacher, T., Ndinga, H., Bidjoka, V., Meyong, F., NGo Bata, M. \& Olson, D. (2017) Camera-Trap Survey for Larger Terrestrial Wildlife in the Dja Biosphere Reserve, Cameroon. Zoological Society of London \& Cameroon Ministry of Forests and Wildlife, Yaoundé, Cameroon.

Buckland, S.T., Anderson, D.R., Burnham, K.P., Laake, J.L., Borchers, D.L. \& Thomas, L. (2001) Introduction to Distance Sampling. Oxford University Press, Oxford, UK.

Cappelle, N., Després-Einspenner, M.L., Howe, E.J., Boesch, C. \& KÜHL, H.S. (2019) Validating camera trap distance sampling for chimpanzees. American Journal of Primatology, 81, 1-9.

Clark, C.J., Poulsen, J.R., Malonga, R. \& Elkan, P.W. (2009) Logging concessions can extend the conservation estate for Central African tropical forests. Conservation Biology, 23, 1281-1293.

Croes, B.M., Laurance, W.F., Lahm, S.A., Tchignoumba, L., Alonso, A., LeE, M.E. et al. (2007) The influence of hunting on antipredator behavior in Central African monkeys and duikers. Biotropica, 39, 257-263.

East, R. (1998) African Antelope Database 1998. IUCN/SSC Antelope Specialist Group., Gland, Switzerland and Cambridge, UK.

Elenga, G., Bonenfant, C. \& Péron, G. (2020) Distance sampling of duikers in the rainforest: dealing with transect avoidance. PLOS ONE, 15, p.eo240049.

FA, J.E., RyAN, S.F. \& BELL, D.J. (2005) Hunting vulnerability, ecological characteristics and harvest rates of bushmeat species in afrotropical forests. Biological Conservation, 121, 167-176.

Feer, F. (1995) Seed dispersal in African forest ruminants. Journal of Tropical Ecology, 11, 683-689.

Grande-Vega, M., Farfán, M.Á., Ondo, A. \& FA, J.E. (2016) Decline in hunter offtake of blue duikers in Bioko Island, Equatorial Guinea. African Journal of Ecology, 54, 49-58.

Howe, E.J., Buckland, S.T., Després-Einspenner, M.L. \& Kühl, H.S. (2017) Distance sampling with camera traps. Methods in Ecology and Evolution, 8, 1558-1565.

Jimoh, S.O., Ikyaagba, E.T., Alarape, A.A., Adeyemi, A.A. \& Waltert, M. (2011) Preliminary information on the density and distribution of duikers in the Oban sector of Cross River National Park, Nigeria. In Tropentag 2011: Conference on International Research on Food Security, Natural Resource Management and Rural Development. 5-7 October 2011, University of Bonn, Bonn, Germany.

Jost Robinson, C.A., Zollner, P.A. \& Kpanou, J.B. (2017) Night and day: evaluating transect methodologies to monitor duikers in the Dzanga-Sangha Protected Areas, Central African Republic. African Journal of Ecology, 55, 222-232.

Kamgaing, T.O.W., Bobo, K.S., Djekda, D., Azobou, K.B.V., Hamadjida, B.R., Balangounde, M.Y. et al. (2018) Population density estimates of forest duikers (Philantomba monticola \& 
Cephalophus spp.) differ greatly between survey methods. African Journal of Ecology, 56, 908-916.

Kingdon, J. \& Hoffmann, M. (eds) (2013) Volume VI: Pigs, Hippopotamuses, Chevrotain, Giraffes, Deer and Bovids. Mammals of Africa. Bloomsbury, London, UK.

LWANGA, J.S. (2006) The influence of forest variation and possible effects of poaching on duiker abundance at Ngogo, Kibale National Park, Uganda. African Journal of Ecology, 44, 209-218.

Marques, T.A., Thomas, L., Fancy, S.G. \& Buckland, S.T. (2007) Improving estimates of bird density using multiple covariate distance sampling. The Auk, 124, 1229-1243.

Minfof (Ministry of Forests and Fauna) \& IUCN (2015) Caractérisation de la Population de Grands et Moyens Mammifères dans la Reserve de Faune du Dja: Potentiel et Menaces. MINFOF \& IUCN, Yaoundé, Cameroon.

Nakashima, Y., Inoue, E. \& A komo-Okoue, E.-F. (2013) Population density and habitat preferences of forest duikers in Moukalaba-Doudou National Park, Gabon. African Zoology, 48, 395-399.

O’Brien, T.G., Ahumada, J., Akampurila, E., Beaudrot, L., Boekee, K., Brncic, T. et al. (2019) Camera trapping reveals trends in forest duiker populations in African National Parks. Remote Sensing in Ecology and Conservation, 168-180.

Poulsen, J.R., Clark, C.J. \& Bolker, B.M. (2011) Decoupling the effects of logging and hunting on an afrotropical animal community. Ecological Applications, 21, 1819-1836.

R Development Core Team (2020) R: A Language and Environment for Statistical Computing. R Foundation for statistical computing, Vienna, Austria.

Remis, M.J. (2000) Preliminary assessment of the impacts of human activities on gorillas Gorilla gorilla gorilla and other wildlife at Dzanga-Sangha Reserve, Central African Republic. Oryx, 34, 56-65.

Remis, M.J. \& Kpanou, J.B. (2011) Primate and ungulate abundance in response to multi-use zoning and human extractive activities in a Central African Reserve. African Journal of Ecology, 49, 70-80.

Rovero, F. \& Marshall, A.R. (2004) Estimating the abundance of forest antelopes by line transect techniques: a case from the Udzungwa Mountains of Tanzania. Tropical Zoology, 17, 267-277.
Rovero, F. \& Marshall, A.R. (2009) Camera trapping photographic rate as an index of density in forest ungulates. Journal of Applied Ecology, 46, 1011-1017.

Rowcliffe, J.M., Kays, R., Kranstauber, B., Carbone, C. \& JANSEN, P.A. (2014) Quantifying levels of animal activity using camera trap data. Methods in Ecology and Evolution, 5, 1170-1179.

Thomas, L., Buckland, S.T., Rexstad, E.A., Laake, J.L., StrindierG, S., Hedley, S.L. et al. (2010) Distance software: design and analysis of distance sampling surveys for estimating population size. Journal of Applied Ecology, 47, 5-14.

UNESCO (2018) Dja Faunal Reserve. whc.unesco.org/en/list/407 [accessed 9 August 2018].

van Vliet, N. \& Nasi, R. (2008) Mammal distribution in a Central African logging concession area. Biodiversity and Conservation, 17, 1241-1249.

van Vliet, N., Nasi, R., Emmons, L., Feer, F., Mbazza, P. \& Bourgarel, M. (2007) Evidence for the local depletion of bay duiker Cephalophus dorsalis, within the Ipassa Man and Biosphere Reserve, north-east Gabon. African Journal of Ecology, 45, 440-443. van Vliet, N., Zundel, S., Miquel, C., Taberlet, P. \& Nasi, R. (2008) Distinguishing dung from blue, red and yellow-backed duikers through noninvasive genetic techniques. African Journal of Ecology, 46, 411-417.

Viquerat, S.M.A., Bobo, K.S., Mller, M., Kiffner, C. \& Waltert, M. (2012) Estimating forest duiker (Cephalophinae) density in korup national park: a case study on the performance of three line transect methods. African Journal of Wildlife Research, 42, 1-10.

Waltert, M., Heber, S., Riedelbauch, S., Lien, J.L. \& Mühlenberg, M. (2006) Estimates of blue duiker (Cephalophus monticola) densities from diurnal and nocturnal line transects in the Korup region, south-western Cameroon. African Journal of Ecology, 44, 290-292.

White, L.J.T. (1994) Biomass of rain forest mammals in the Lopé Reserve, Gabon. Journal of Animal Ecology, 63, 499-512.

Wilkie, D. \& Carpenter, J. (1999) Bushmeat hunting in the Congo Basin. Biodiversity and Conservation, 8, 927-955.

YASUOKA, H. (2006) The sustainability of duiker (Cephalophus spp.) hunting for the baka hunter-gatherers in southeastern Cameroon. African Study Monographs, 33, 95-120. 